\title{
DESIGN OF A FRETTING FATIGUE TEST RIG WITH COMPLIANT SPRINGS
}

\author{
J. De Pauw ${ }^{1}$, P. De Baets ${ }^{1}$, W. De Waele ${ }^{1}$ and R. Hojjati-Talemi ${ }^{1}$ \\ ${ }^{1}$ Ghent University, Soete Laboratory, Belgium
}

\begin{abstract}
Fretting is a small amplitude oscillatory movement which occurs between contacting bodies who are subjected to cyclic loading or vibrations. In the contact area arise stresses -normal and tangentialcausing stress concentrations and surface degradation. Fretting in combination with ordinary fatigue will reduce the plain fatigue lifetime due to the additional stresses and surface degradation. Applications susceptible to fretting fatigue are for instance connections techniques. By nature they have contacting bodies and transfer loads or vibrations. Connection techniques commonly seen in the field of fretting fatigue are lap-joints, dovetail connections and spline connections.
\end{abstract}

Although mitigating or managing fretting fatigue is industrially relevant, academic research is confined and only revealed basic insights. Therefore, we developed a fretting fatigue test rig at Soete Laboratory. The paper describes the design of the test rig and points out some important features. To study the general phenomenon of fretting fatigue we selected a coupon scale test rig rather than a full scale test rig where only one application can be studied. The specimens used are one dog bone specimen and two indentation pads which make contact with the dog bone specimen. The normal force $F_{N}$ between the specimen and the pads is close loop controlled with a hydraulic actuator. A second hydraulic actuator controls the dynamic force $F_{\text {fat }}$ in the dog bone specimen. A third force $F_{T}$ is introduced during dynamic loading between the dog bone specimen and the pads by means of compliant springs. The combination of these three forces: $F_{N}$, $F_{\text {fat, }}, F_{T}$ in the contact area gives rise to the fretting fatigue phenomenon. The test rig at Soete laboratory can be used to study fretting fatigue and examine mitigations such as surface texturing, surface work hardening, etc.

Keywords: Fretting fatigue; test rig; experimental

\section{INTRODUCTION}

Fretting fatigue is the combined action of two mechanical phenomena: fretting and fatigue. The first, fretting, is a tribological phenomenon that occurs between two contacting bodies. The bodies are normally prestressed onto each other while a small cyclic tangential relative motion takes place. As a result, localized stresses (normal and tangential) arise at the contact and its vicinity. Small cracks initiate at the stress concentrations and surface degradation takes place. The second occurring phenomenon is fatigue. Fatigue occurs when one body is cyclically loaded. Fatigue leads to localized structural damage which develops in three stages: crack initiation, crack propagation and ends with final rapture.

The interaction of fretting and fatigue ensures a reduced total lifetime [1]. The total lifetime for ordinary fatigue can be divided in two portions: a crack initiation lifetime and a crack propagation lifetime. At high cycle fatigue $\left(10^{4} . .10^{7}\right)$ is the portion of crack initiation typically longer compared to crack propagation [2]. However, in fretting fatigue is the lengthier crack initiation lifetime reduced due to fretting. Fretting initiates small cracks faster than ordinary fatigue due to the high stress concentrations at the contact. This significantly reduces the total lifetime of fretting fatigue applications compared to ordinary fatigue applications.

Industrial applications where fretting fatigue failure occurs are commonly found in the field of connection techniques. By nature, connection techniques are used to join two or more bodies. The bodies make contact with each other and they transfer a (dynamic) load or vibration. In short, all the elements needed for a fretting fatigue failure are present. In the aerospace industry are lap joints and dovetail connections frequently seen to be sensitive to fretting fatigue [3], see Figure $1 \mathrm{a} \& \mathrm{~b}$. In mechanical engineering is fretting fatigue seen at the press fit between compliant shafts and ridged applications such as gears and bearings [4], see Figure 1c. 
a.

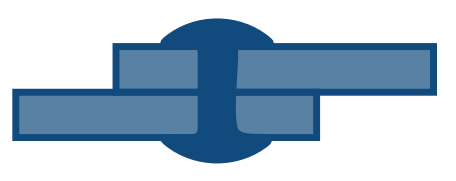

b.

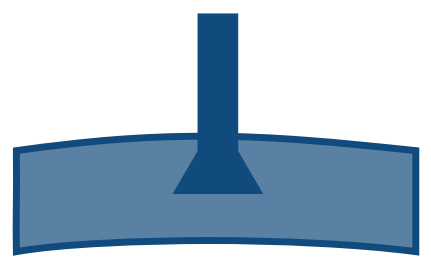

C.

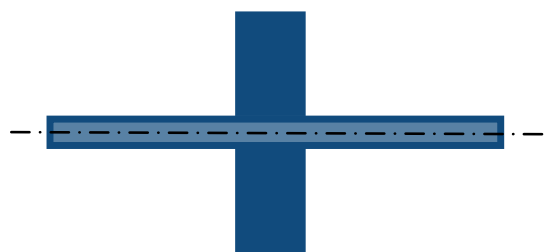

Figure 1. Overview of some applications where fretting fatigue has been observed.

\section{FRETTING FATIGUE TEST RIGS}

To study fretting fatigue one needs to generate fretting fatigue in a controlled environment. However, a standardized fretting fatigue test rig or standardized procedure thus not exists. Since the first fretting fatigue conference (1990, [5]) until now, there is no globally accepted standardization concerning fretting fatigue experiments [6]. Therefore, researchers are forced to develop their own custom fretting fatigue test rig. A plurality of test rigs is thus created [7], see Figure 2. The fretting fatigue test rig at Soete Laboratory is a "One actuator test rig with adjustable compliance".

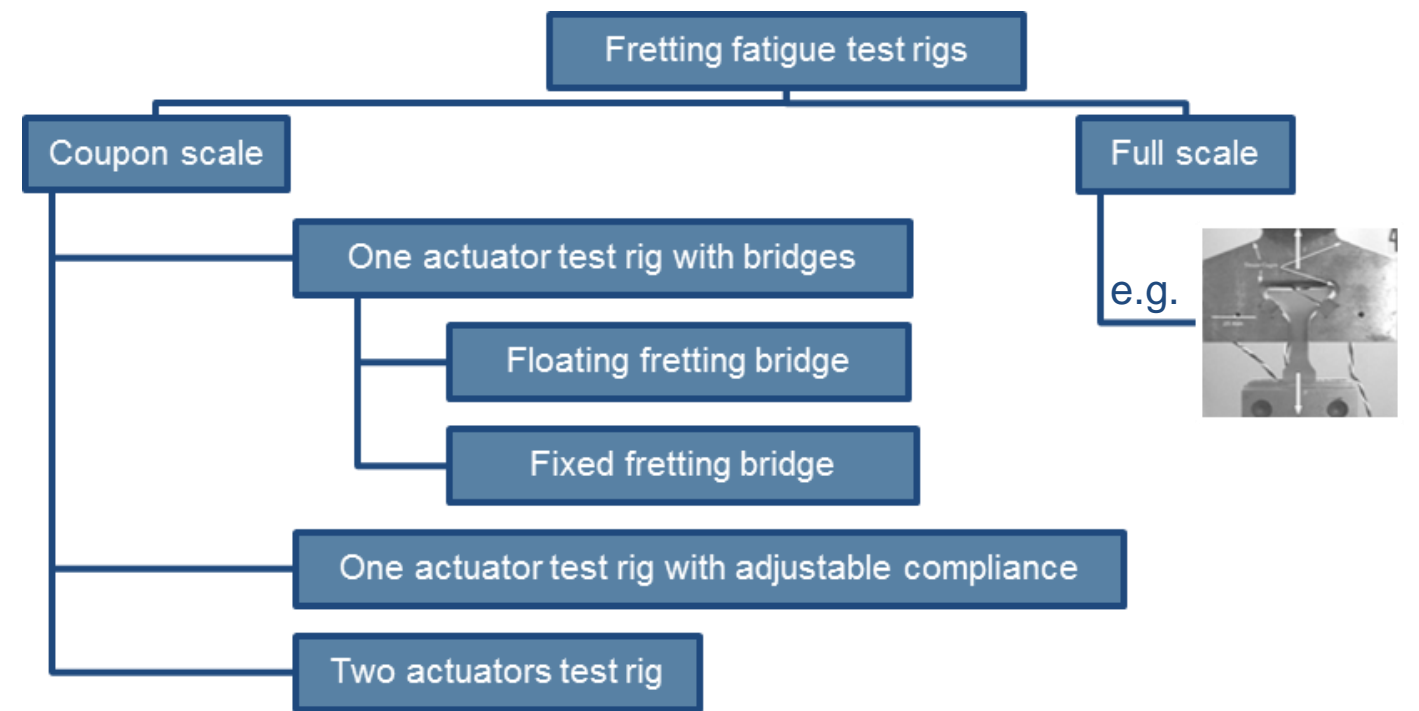

Figure 2. Classification of fretting fatigue test rigs.

To generate fretting fatigue on coupon scale, one need two or more contacting bodies and has to apply three forces simultaneous, see Figure 3. In most test setups are tree bodies used for symmetry reasons (avoid bending). Centrally is a specimen mounted whereupon two indenters (pad) interact. The specimen is dynamically loaded $\left(F_{\text {fat }}\right)$ which introduces the fatigue phenomenon. On the pads are two forces applied. The first is a constant force, $F_{N}$, which normally pre-stresses the pads onto the specimen. The second force, $F_{T}$, is dynamic and introduces a tangential component between the pad and the specimen.

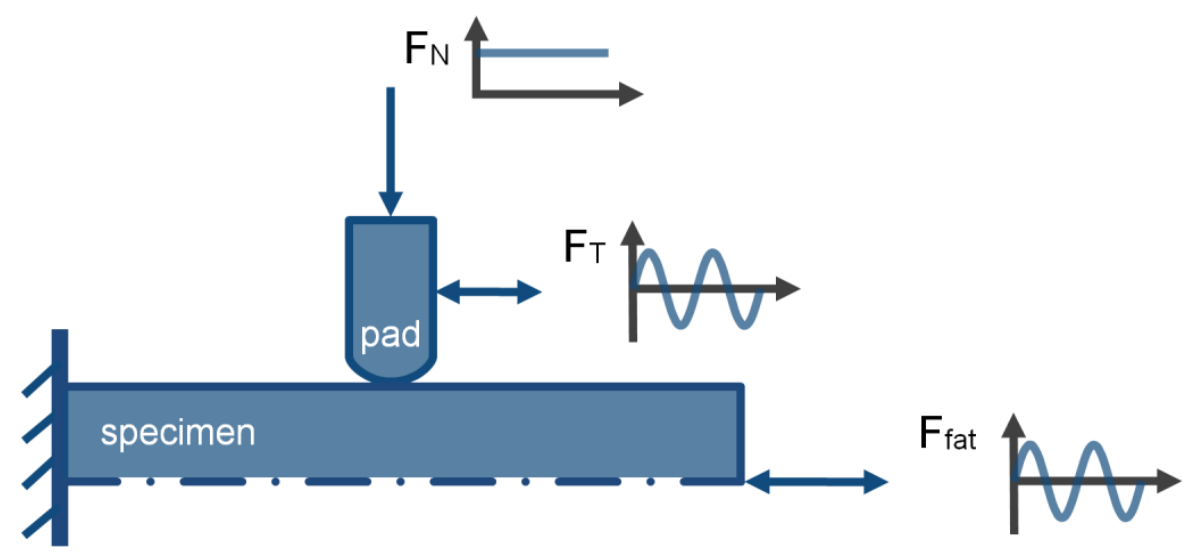

Figure 3. Overview of interacting forces $F_{N}, F_{\mathrm{T}} \& F_{\text {fat }}$ on a coupon scale fretting fatigue contact. 
The type of contact between the pad and the specimen depends on the geometry of both bodies. The test rig at Soete Laboratory uses a flat strip (dog bone) specimen and cylindrical ended pads, see Figure 4. The contact between both bodies is a Hertz line contact.

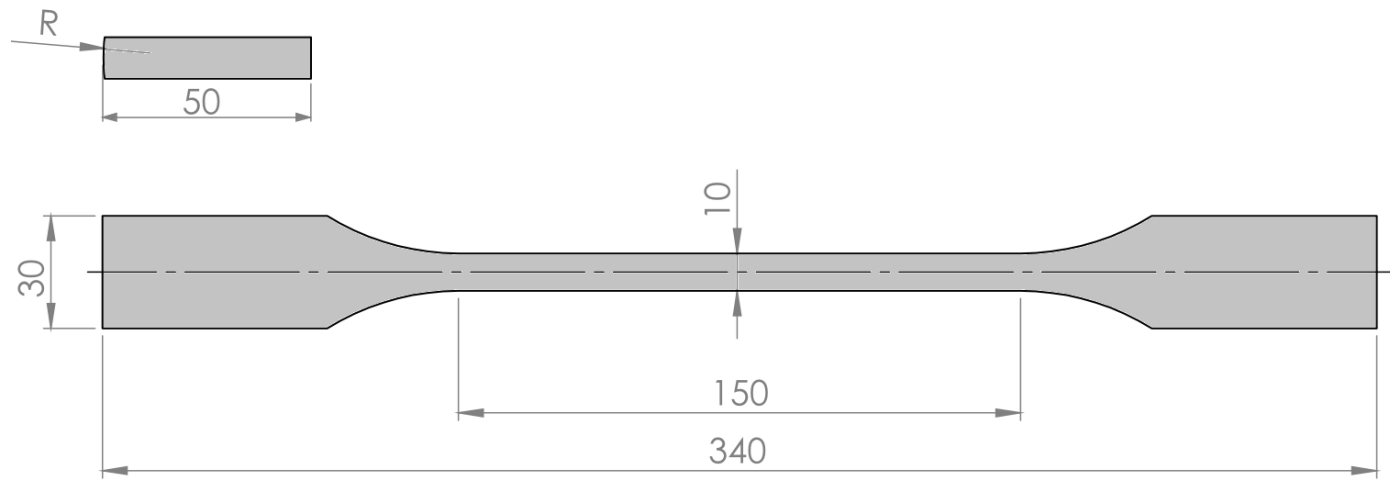

Figure 4. Geometry of the specimen and the pad.

\subsection{Mechanical layout}

The construction of the fretting fatigue test rig is an ordinary load frame with an additional fretting fixture, see Figure 5. The load frame grips the fatigue specimen while the fixture grips the pads and applies the forces $F_{N}$ and $F_{T}$. The load frame $(\mathrm{ESH})$ has one hydraulic actuator of $100 \mathrm{kN}$ connected with the upper gripper. The lower gripper is fixed on the load frame. The (dogbone) specimen is installed in the two mechanical wedge grippers and the fatigue force $F_{\text {fat }}$ is applied at the upper gripper.

The fretting fixture holds the two pads and applies the forces $F_{N}$ and $F_{T}$. The two pads are positioned symmetrical to the specimen and are fixed on the elastic elements (monolithic four bar linkage with elastic joints). The elastic elements ensure that the pads remain horizontal and allow displacement in horizontal direction. This (normal) displacement is needed to accommodate fretting wear or accumulation of particles in the contact i.e. the pad shifts towards or away from the specimen, respectively.

The tangential force $F_{T}$ is introduced by means of leaf springs. The leaf springs connect the pads and elastic elements with the base plate of the fixture. During fatigue loading moves the contact point of pad and specimen cyclic in tangential direction. Since there is no gross slip between the pads and the specimen (fretting condition) are the pads also moving in tangential direction. The tangential force is generated by the compliance of the springs and the elastic deformation of the specimen. The tangential force $F_{T}$ is proportional and in-phase with the fatigue force $F_{\text {fat }}$. The tangential force can be varied relative to the fatigue force by changing the stiffness of the springs.

The normal force $F_{N}$ is applied with a $10 \mathrm{kN}$ servo-hydraulic actuator. The actuator is installed on a C-beam to generate two opposite normal forces $F_{N}$. The C-beam construction is freely movable on the base plate (low friction material) to ensure equal loads and avoid bending in the specimen. The normal force engages on the elastic elements through a roller support. The roller support accommodates the small cyclic tangential motion of the elastic elements.

The normal force is applied with a C-beam construction which is asymmetric in lieu of a symmetrical construction. This way one side of the experiment (perpendicular to the contact area, Figure 3) remains visible from the outside of the test rig. Field measuring techniques can then be used to visualise stress and strain in the vicinity of the contact. 


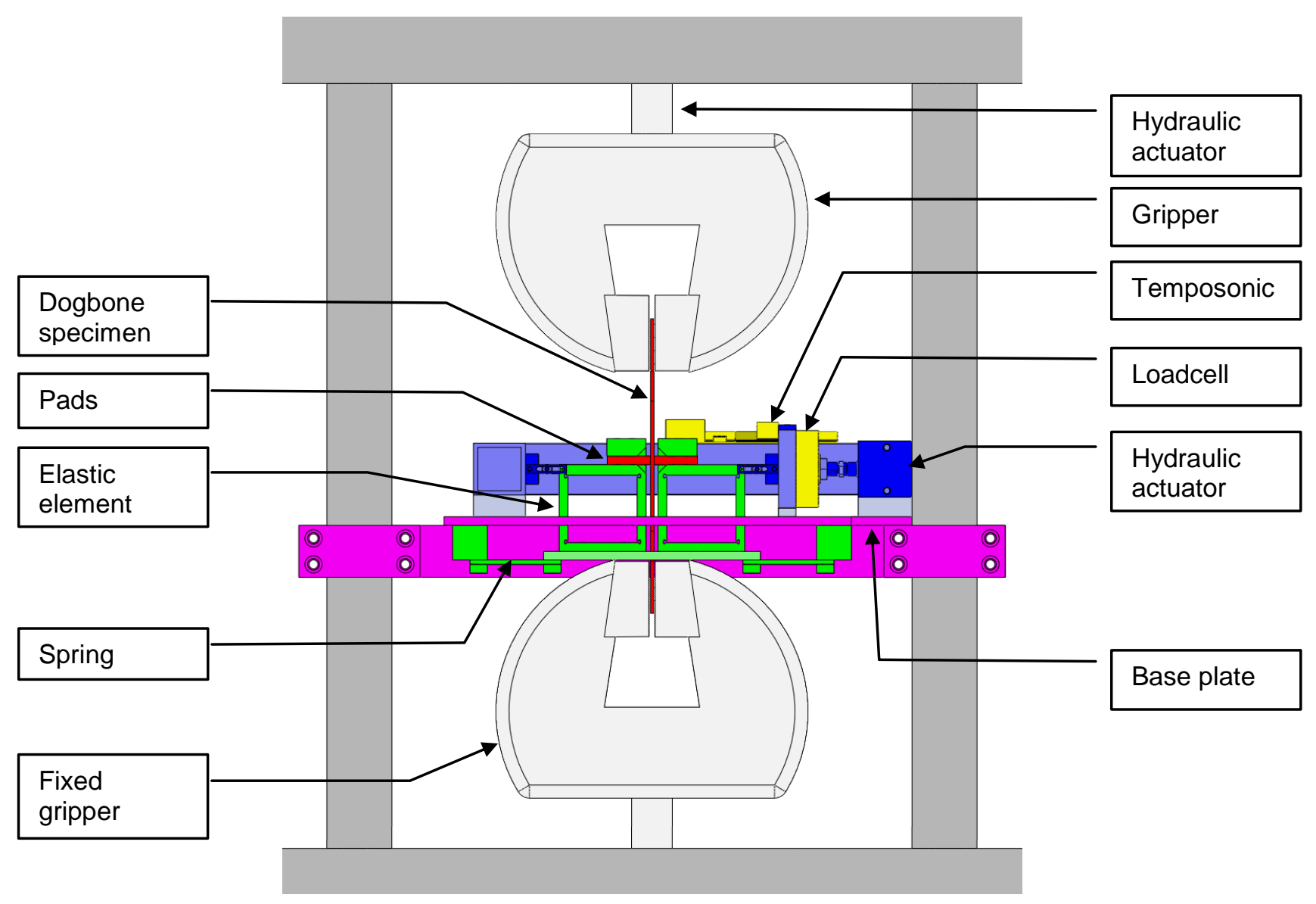

Figure 5. Overview of the fretting fatigue test rig at Soete laboratory.

\subsection{Measurement and instrumentation}

The control of the test rig and the data acquisition are carried out by the same computer (MTS Flextest). Data acquisition is performed for seven parameters of the test, see Table 1.

Table 1. Logged signals during a fretting fatigue experiment

\begin{tabular}{lll} 
Parameter & symbol & unit \\
\hline Time & $\mathrm{t}$ & $\mathrm{s}$ \\
\hline Number of cycles & cycles & - \\
\hline Fatigue Force & $F_{\text {fat }}$ & $\mathrm{N}$ \\
\hline Normal Force & $F_{N}$ & $\mathrm{~N}$ \\
\hline Tangential Force & $F_{T}$ & $\mathrm{~N}$ \\
\hline Displacement fatigue force actuator & $\mathrm{d}_{\mathrm{fat}}$ & $\mathrm{mm}$ \\
\hline Displacement normal force actuator & $\mathrm{d}_{\mathrm{N}}$ & $\mathrm{mm}$ \\
\hline
\end{tabular}

The seven parameters are periodically logged during the experiment. Continuous logging of all parameters would result in unmanageable huge data sets $\left(10^{6}\right.$ cycles would give $\left.>170 \mathrm{~GB}\right)$. Therefore we use a custom data logging protocol to minimize the data volume and keep the most relevant data. Two different logging procedures are used for this purpose. The first is logging continuously (sample frequency $100 \mathrm{~Hz}$ ) the beginning of a test (running-in) and then one cycle per hundred cycles. The second logging procedure runs during the entire test and acquires per cycle only the peak and valley value. As a result, the stored data is reduced considerably without losing much information about the experiment.

The first two signals (time and number of cycles) are internally taken from the control computer. The fatigue force is measured by the load cell of the tensile test rig. The normal force is measured with a load cell which is fitted on the floating C-beam construction, see Figure 5 . The tangential force is not measured with 
a load cell but is correlated to the strain in the leaf springs. The leaf springs are equipped with a strain gage and are calibrated to the tangential force. The compliance of the tangential force can be seen in Figure 6.

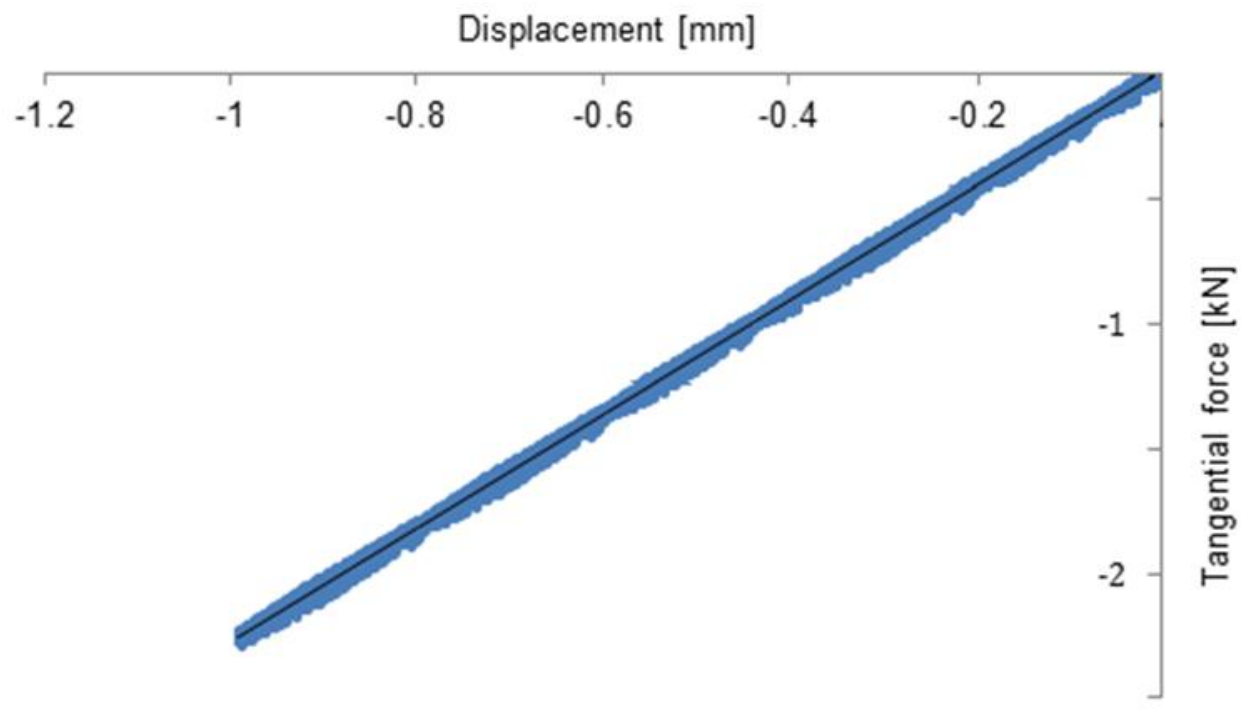

Figure 6. Calibration curve of the leaf springs

\section{CONCLUSIONS}

A new test rig is designed to test fretting fatigue. Fretting fatigue is generated on coupon scale between one fatigue specimen and two cylindrical pads. The experiment is performed by applying three forces: $F_{\text {fat }}, F_{N}$ and $F_{T}$ simultaneously on the specimens. The logging of the data (time, $\mathrm{nr}$. of cycles, forces, and displacements) is done in a custom periodic manner. The beginning of the test and one in a hundred cycles is continuously sampled while also logging the peak and valley values of every cycle.

The test rig can be used to study fretting fatigue on a fundamental and applied way. Field measuring techniques as thermography and digital image correlation visualise stress and strain and can be used to validate and optimize finite element simulations. Mitigations of fretting fatigue e.g. surface modifications can be tested and compared in order to increase fretting fatigue lifetime.

\section{NOMENCLATURE (OPTIONAL)}

$\begin{array}{lll}\text { cycles } & \text { Number of cycles } & - \\ \mathrm{d}_{\mathrm{fat}} & \text { Displacement fatigue actuator } & \mathrm{mm} \\ \mathrm{d}_{\mathrm{N}} & \text { Displacement normal actuator } & \mathrm{mm} \\ F_{\text {fat }} & \text { Fatigue force } & \mathrm{N} \\ F_{N} & \text { Normal force } & \mathrm{N} \\ F_{T} & \text { Tangential force } & \mathrm{N} \\ \mathrm{t} & \text { Time } & \mathrm{s}\end{array}$

\section{ACKNOWLEDGEMENTS}

The authors would like to acknowledge the support of the IWT (Agency for Innovation by Science and Technology $-\mathrm{n}^{\circ}$ SB-091510).

\section{REFERENCES}

1. Waterhouse, R.B., Fretting Corrosion. International series of monographs on materials science and technology, ed. D.W. Hopkins. Vol. 10. 1972, London: Pergamon Press. 244.

2. Ibrahim, M.F.E. and K.J. Miller, Determination of fatigue crack initiation life. Fatigue \& Fracture of Engineering Materials \& Structures, 1979. 2(4): p. 351-360. 
3. Farris, T.N., M.P. Szolwinski, and G. Harish, Fretting in aerospace structures and materials, in Fretting Fatigue: Current Technology and Practices, D.W. Hoeppner, V. Chandrasekaran, and C.B. Elliott, Editors. 2000, American Society Testing and Materials: W Conshohocken. p. 523-537.

4. Hoeppner, D.W., Fretting fatigue case studies of engineering components. Tribology International, 2006. 39(10): p. 1271-1276.

5. Attia, M.H. and R.B. Waterhouse, Standardization of fretting fatigue test methods and equipment. 1992.

6. Neu, R.W., Progress in standardization of fretting fatigue terminology and testing. Tribology International, 2011. 44(11): p. 1371-1377.

7. De Pauw, J., P. De Baets, and W. De Waele, Review and classification of fretting fatigue test rigs, in SUSTAINABLE CONSTRUCTION AND DESIGN, J. Van Wittenberghe, Editor. 2011, Ghent University, Laboratory Soete: Ghent, Belgium. p. 41-52. 